\title{
Chromium picolinate therapy in pre/diabetes care: recognition of individual risks and outcomes
}

\author{
Olga Golubnitschaja ${ }^{*}$, Kristina Yeghiazaryan ${ }^{\dagger}$, Hans H. Schild \\ From EPMA-World Congress 2013 \\ Brussels, Belgium. 20-21 September 2013
}

\section{Scientific background}

Due to the important physiologic function of trivalent chromium in glucose/insulin homeostasis, some commercial organisations promote $\mathrm{Cr}^{+}$supplements in maintaining proper carbohydrate and lipid metabolism; regulation of reducing carbohydrate carvings and appetite; prevention of insulin resistance and glucose intolerance; regulation of body composition, including reducing fat mass and increasing lean body mass; optimal body building for athletes; losing weight; treatment of atypical depression as an antidepressant; and prevention of obesity and type 2 diabetes mellitus. On one hand, case reports are commented as 'nonevidencebased anecdotes'. On the other hand, a number of independent studies warn against adverse health outcomes assigned to chromium picolinate (CrPic) dietary application [1].

\section{Materials and methods}

To simulate treatment affects by CrPic a well-acknowledged animal diabetes model of $\mathrm{db} / \mathrm{db}$-mice was utilised. Animals were grouped into eight groups. Group 1 represented the healthy control. Group 2 was the model mice for type 2 DM. Groups $3-7$ were diabetes-model mice treated under individual algorithms: $5 \mathrm{mg} / \mathrm{kg} \mathrm{CrPic}$ from 6 weeks to 6 months of age (Group 3), $10 \mathrm{mg} / \mathrm{kg} \mathrm{CrPic}$ from 6 weeks to 6 months of age (Group 4), $100 \mathrm{mg} / \mathrm{kg}$ CrPic from 6 weeks to 6 months of age (Group 5), 100 $\mathrm{mg} / \mathrm{kg}$ CrPic from 3 months to 6 months of age (Group 6), and $250 \mathrm{mg} / \mathrm{kg}$ CrPic from 3 months to 6 months of age (Group 7). Kidney tissue samples were collected and stored at $-80^{\circ} \mathrm{C}$ till quantitative comet assay sub-cellular imaging was performed to evaluate individual and group-specific effects by $\mathrm{CrPic}$ treatments.

\section{Results}

We have demonstrated highly individual reactions towards CrPic dietary supplements and highlighted risks when the dietary supplements are used freely as therapeutic agents, without application of advanced diagnostic tools to predict individual outcomes (Figure 1) [2].

\section{Conclusions and recommendations: artificial supplements for diabetes prevention - hype or hope?}

High efficacy of a balanced diet, an individually optimised lifestyle and personalised treatment regiments can hardly be substituted by a limited number of single supplements to cover all the multifactorial risks such as the upward trends of population ageing, environmental risk factors, urbanisation, additive effects of diverse stress factors, incorrectly chosen lifestyle including unfavourable nutritional habits, increasing prevalence of obesity, low physical activity, etc [3]. The population at-risk for diabetes is huge and increasing in a pandemic scale. One of the reasons might be the failed attempt to prevent the disease by the application of artificial supplements and drugs with hardly recognised individual risks. Consequently, a multimodal approach of integrative medicine by predictive diagnostics, targeted prevention and individually created treatment algorithms is highly desirable. Targeted measures require a creation of new guidelines that are essential to regulate (renoprotective) therapy approaches and the application of more individualised therapeutic modalities for advanced diabetes care. These measures should provide a legitimate regulation for well-timed predictive diagnostics, an effective prevention and the creation of individualised treatment algorithms in pre/diabetes care [4].

\footnotetext{
* Correspondence: olga.golubnitschaja@ukb.uni-bonn.de

+ Contributed equally

Radiologic Clinic, University of Bonn, Germany
} 


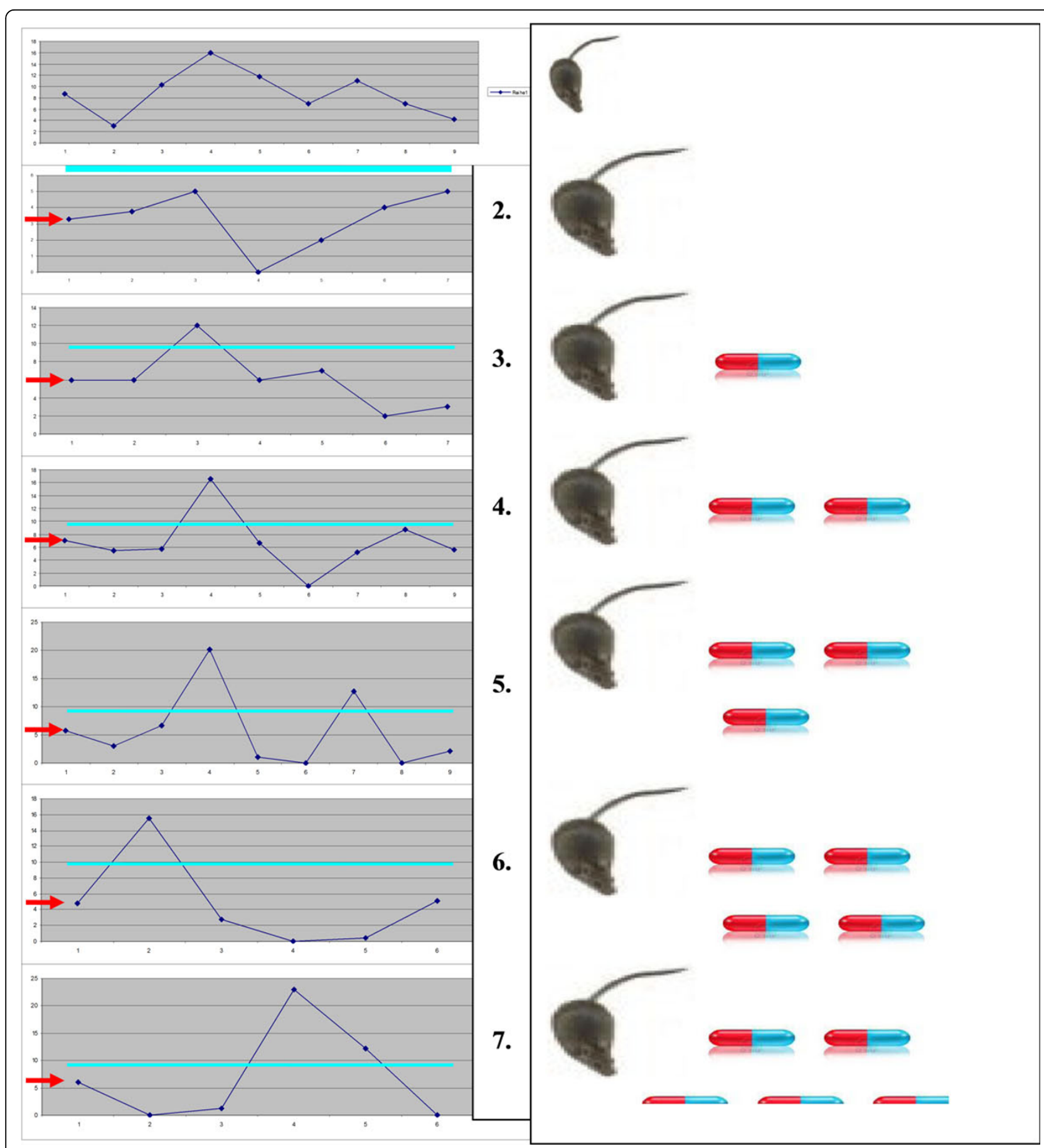

Figure 1 Diagram demonstrates individual reactions towards CrPic treatments in the groups of comparison. Individual levels of intact DNA (axe $X$, individual numbering; axe $\mathrm{Y}$, comet class I in \%) are highly heterogeneous in diabetic groups compared to control group 1. The highest level of heterogeneity is evident in groups 5, 6 and 7 with the highest doses of CrPic supplements. The turquoise lines mark the level corresponding to the mean value of the control group; in contrast, the red arrows mark the level corresponding to the mean of the untreated diabetic group [2]. 


\section{Acknowledgements}

The project has been granted by NIH ("Is chromium-picolinate renoprotective in diabetes?", National Institutes of Health, study no. 1R21 AT003012-01A1). The authors thank to Prof. Dr. M. Mozaffari (Georgia Health Sciences University, USA) for providing tissue samples in the project. For the statistical analysis and assistance in preparation of the original paper [5], the authors thank V. Peeva, M.Sc., University of Bonn, Germany.

Published: 11 February 2014

\section{References}

1. Yeghiazaryan K, Schild HH, Golubnitschaja O: Recognition of individual risks by analysis of subcellular imaging insights into chromium picolinate therapy in pre/diabetes care, search into its safety and opinion controversy. New Strategies to Advance Pre/Diabetes Care: Integrative Approach by PPPM in Diabetes Edited by Mozaffari M; Book-Series "Advances in Predicitive, Preventive and Personalised Medicine" Springer; 2013.

2. Golubnitschaja O, Yeghiazaryan K: Opinion controversy to chromium picolinate therapy's safety and efficacy: ignoring 'anecdotes' of case reports or recognising ndividual risks and new guidelines urgency to introduce innovation by predictive diagnostics? EPMA J 2012, 3:11

3. Yeghiazaryan K, Cebioglu M, Golubnitschaja O: Global Figures Argue in Favour of Preventive Measures and Personalised Treatment to Optimise Inadequate Diabetes Care. In New Strategies to Advance Pre/Diabetes Care: Integrative Approach by PPPM. Springer;:Mozaffari M 2013:

4. Golubnitschaja O, Costigliola V: Common origin but individual outcomes: time for new guidelines in personalized healthcare. Personalized Med 2010, 7:561-568.

5. Yeghiazaryan K, Peeva V, Shenoy A, Schild HH, Golubnitschaja O: Chromium-picolinate therapy in diabetes care: molecular and subcellular profiling revealed a necessity for individual outcome prediction, personalised treatment algorithms and new guidelines. Infect Disord Drug Targets 2011, 11:188-195.

doi:10.1186/1878-5085-5-S1-A77

Cite this article as: Golubnitschaja et al:: Chromium picolinate therapy in pre/diabetes care: recognition of individual risks and outcomes. EPMA Journal 2014 5(Suppl 1):A77.

\section{Submit your next manuscript to BioMed Central and take full advantage of:}

- Convenient online submission

- Thorough peer review

- No space constraints or color figure charges

- Immediate publication on acceptance

- Inclusion in PubMed, CAS, Scopus and Google Scholar

- Research which is freely available for redistribution

Submit your manuscript at www.biomedcentral.com/submit 